\title{
James Fenton
}

1949

James Fenton was born in Lincoln and educated at Repton School and Magdalen College, Oxford. He has worked as a newspaper reporter and theatre reviewer. Terminal Moraine, his first volume of poems, was published in 1972. The Memory of War (1982) attracted wide critical acclaim.

\section{THE KILLER SNAILS}

The killer snails

Have slung their silver trails

Along the doormat, out across the lawn,

Under the bushes

5 Where the alarming thrushes

Give night its notice, making way for dawn,

And the obliging lizards drop their tails.

On webs of dew

The spiders stir their pots of glue

10 And drag their quartered victims to the shade.

Soaked in their rugs

Of grass and moss the slugs

Wind up another night of sluggish trade

And young ingredients get into a stew.

15 The sorrel bends.

The path fades out but never ends

Where brambles clutch and bracken wipes your feet.

It goes in rings.

Its mind's on other things.

20 Its way and its intentions never meet.

Meeting of friends?

It gives no undertaking. It depends. 